EESTI NSV TEADUSTE AKADEEMIA TOIMETISED. 30, KOIDE

GEOLOOGIA. 1981, NR. 3

ИЗВЕСТИЯ АКАДЕМИИ НАУК ЭСТОНСКОИ ССР. ТОМ 30

ГЕОЛОГИЯ. 1981, $\mathrm{N2} 3$

\title{
ВОЗРАСТНЫЕ ВЗАИМООТНОШЕНИЯ СТРАТОТИПИЧЕСКИХ ОБНАЖЕНИЙ ЯАГАРАХУ, ПАНГАМЯГИ И МААЗИ (СРЕДНИИ ВЕНЛОК ЭСТОНИИ)
}

Изучение кернов многочисленных буровых скважин, пробуренных на о-ве Сааремаа в ходе геологического картирования в начале семидесятых годов, позволило уточнить наши представления о возрастных взаимоотношениях ряда стратотипических разрезов силура Эстонии, в том числе стратотипов литостратиграфических подразделений яагарахуского горизонта. Результаты ревизии номенклатуры и стратиграфического объема этих подразделений изложены нами ранее (см. Аалоэ и др., 1976), а фактическое обоснование принятым изменениям из-за ограниченного объема статьи не было дано. Ниже приводятся литологическое и циклостратиграфическое сопоставления стратотипических обнажений Яагараху, Пангамяги и Маази с буровыми скважинами, вскрывающими часть среднего и весь нижний мезоциклит * яагарахуского горизонта, а также верхнюю часть нижележащего яаниского горизонта (рис. $1 A$ и 2 ).

Нижней границей указанного нижнего мезоциклита (вильсандиских слоев) служит литологически четкая кровля ниназеской пачки. Нижняя часть мезоциклита сложена мергелями парамаяской пачки **, а верхняя - биогермными и межбиогермными известняками и доломитами кесселайдской пачки. В самой кровле мезоциклита на всей территории о-ва Сааремаа, кроме п-ва Сырве, прослеживается выдержанный, литологически хорошо выделяюшийся пласт зеленовато-серых глинистых тонко- или микрослойчатых доломитов и домеритов с мелкой пиритовой узорчатостью (биотурбитов). Этот первый в разрезе венлока Эстонии пласт первичных лагунных доломитов - наилучший литологический маркер в пределах всей яагарахуской свиты. По буровым разрезам этот пласт прослеживается и на юго-западе материковой части Эстонии (скв. Паатсалу, инт. .16,7-17,0 м; Варбла, инт. 75,576,0 м), причем везде над биогермным комплексом кесселайдской

* Циклит - краткий и удобный термин, предложенный С. Л. Афанасьевым (1976), для обозначения геологического тела, образовавшегося в течение одного седиментационного цикла. По рангу выделяются микро-, мезо-, макро-, мега- и другие циклиты. Мезоциклит обычно состоит из нескольких микроциклитов и соответствует регионально выраженному этапу развития осадконакопления в данном участке бассейна. В венлоке и лудлове Северной Прибалтики в объеме мезоциклитов выделены слои локальные, литологически неоднородные полифациальные возрастные подразделения горизонтов (Эйнасто, 1970, 1976; Аалоэ и др., 1976).

** Автор настоящей статьи считает целесообразным вернуться к первоначальному подразделению яаниского горизонта, предложенному А. О. Аалоэ (1961), и выделять в пределах яаниской свиты мустъяласкую, ниназескую и парамаяскую пачки, т. е. ограничнть последнюю только мергелями над ниназеской пачкой, 


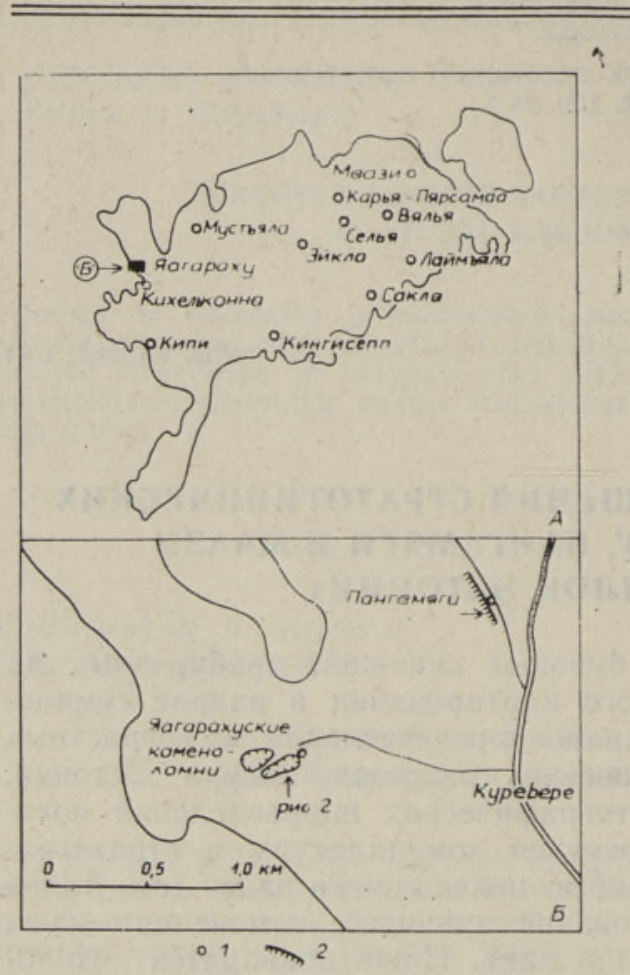

Рис. 1. Расположение стратотипических разрезов яагарахуского горизонта. I скважины, 2 - обрывы.

пачки. Глубина верхней границы этого пласта (границы мезоциклитов) в буровых скважинах следующая: Кипи 87,1, Пангамяги 15,3, Қыыру 50,0 , Селья 30,3, Мустъяла 21,5, Карья-Пярсамаа 10,7, Кингисепп 108,0, Сакла 94,9, Лаймъяла 55,6, Эйкла 47,3, Вялья 37,0, Маази 4,6 м.

В разрезе скважины, заложенной на стратотипическом обнажении свиты в непосредственной близости от северо-восточной стенки заброшенного карьера Яагараху (рис. 15,2 ), непосредственно над кровлей ниназеской пачки залегают коралловые и биогермные известняки яагарахуской свиты, а мергели парамаяской пачки отсутствуют (рис. 2; Аалоэ, 1970 , рис. 68$)$. В отличие от А. Аалоэ $(1960,1970)$ автор настоящей статьи считает наиболее вероятным замещение мергелей парамаяской пачки в районе Яагараху породами не ниназеской пачки, а биогермными известняками низов яагарахуской свиты. Выдержанная мощность $(6,5-7,0$ м), четкие границы и особенности строения ниназеской пачки (нижняя и верхняя часть более карбонатные, средняя более глинистая), закономерные латеральные фациальные изменения в ее пределах (от чистодетритовых отмельных известняков в районе Яагараху к илисто-детритовым комковатым известнякам открытого шельфа в южном и юго-восточном направлениях) позволяют уверенно заключить, что границы ниназеской пачки в пределах северо-западной части о-ва Сааремаа синхронные. Кроме того, кровля ниназеской пачки является границей циклитов (Einasto и др., 1976).

Значительное возрастное скольжение границы яаниской и яагарахуской свит южнее выходов недавно было доказано В. Нестор (1981). По ее мнению, значительная часть мергелей парамаяской пачки (свиты, по Аалоэ, 1970) в скв. Охесааре относится к яагарахуской свите. $\mathrm{B}$ районе выходов эта проблема требует дальнейшего изучения.

Ключем для определения точного стратиграфического положения стратотипического обнажения Яагараху в пределах свиты служит обна- 


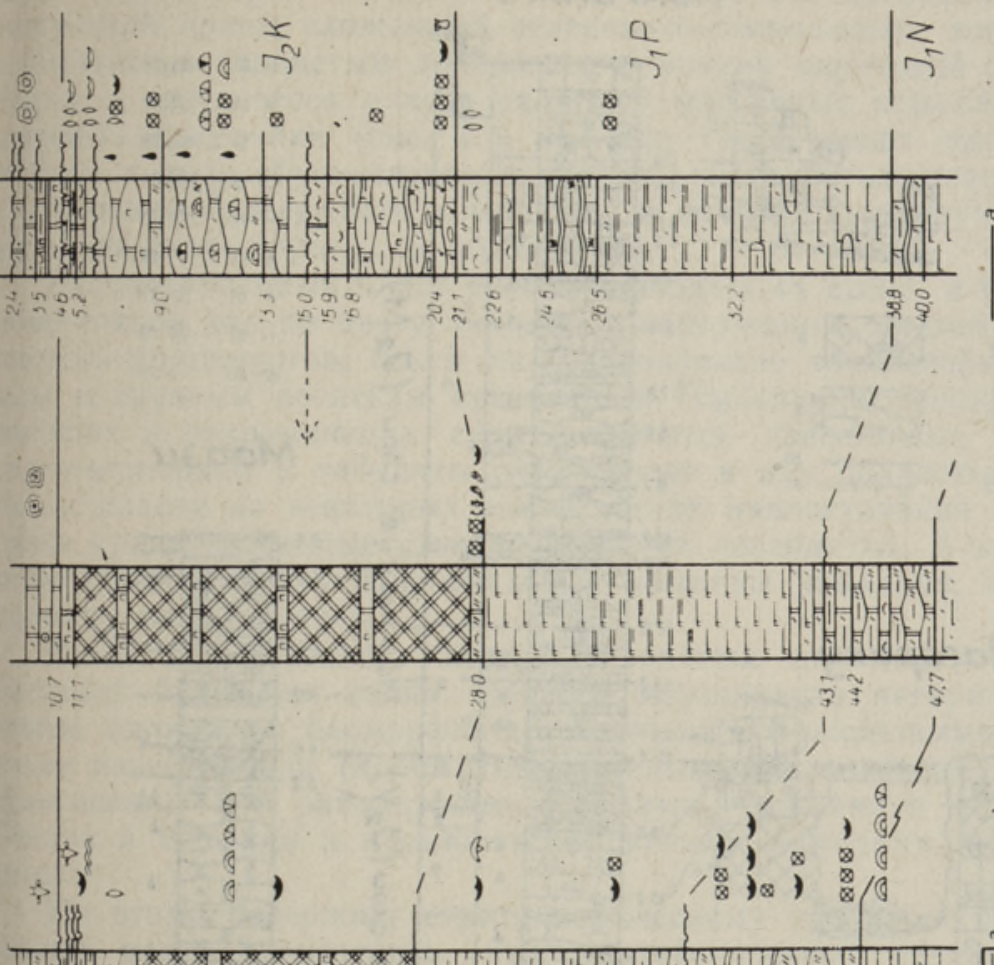

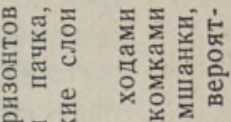

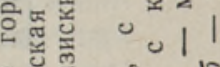

유유

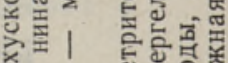

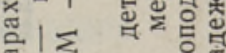

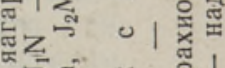

$=$ 뼈ำ

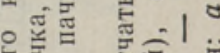

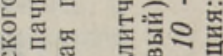

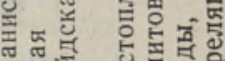

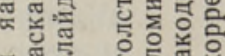

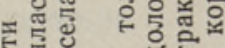

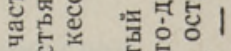

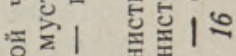

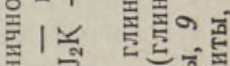

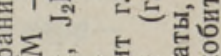

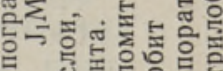

궁 등응하의

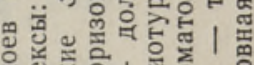

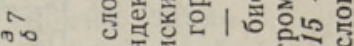
푷의 है

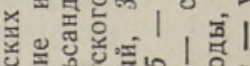

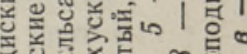

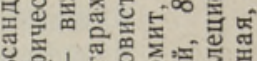

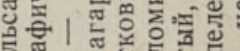

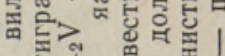

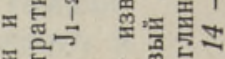

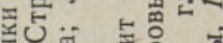

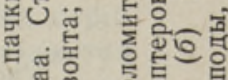

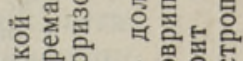
웡잉

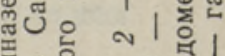

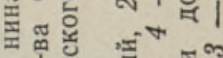
向告

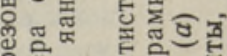
ํํㄹ

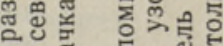

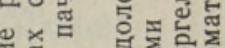

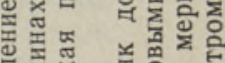

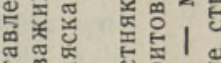

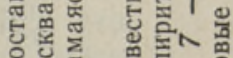

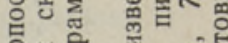

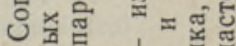
ง哭।

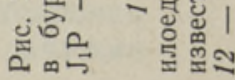




\section{Пангамяги}

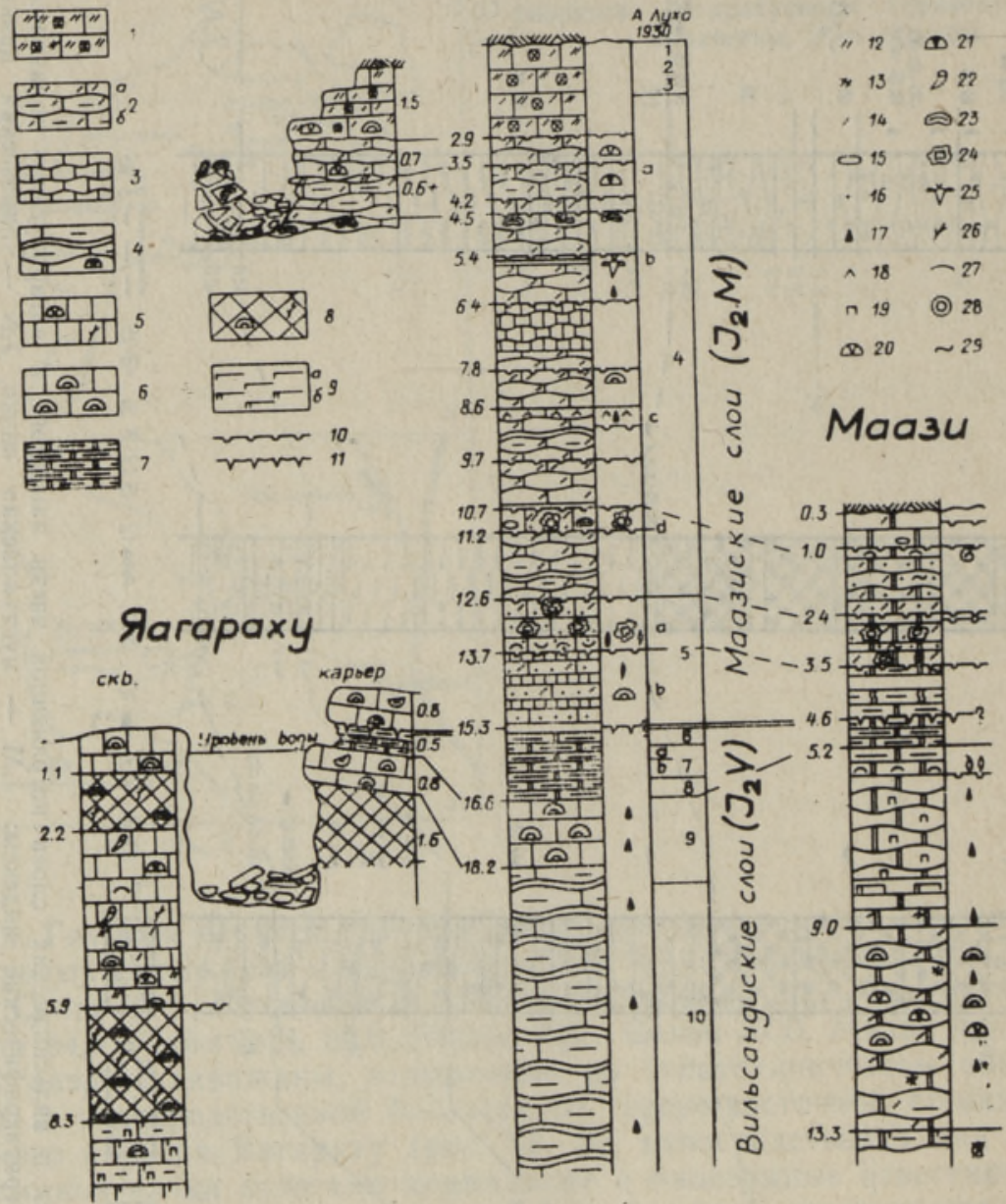

Рис. 3. Сопоставление разрезов обнажений Яагараху и Пангамяги с разрезами буровых скважин Яагараху, Пангамяги и Маази в отношении границы мезоциклитов и маркирующего пласта тонкослойчатого домерита.

1 - известняк крупнодетритовый криноидный, 2 - известняк глинистый комковатый мелкодетритный (a) и илисто-мелкодетритовый (б), 3 - известняк (мелкокомковатый скрытокристаллический), 4 - известняк сильноглинистый и доломит коралловый крупнокомковатый, 5 - известняк скрытокристаллический с кораллами и водорослями, 6 - известняк строматопоровый, 7 - известковый глинистый доломит в кровле седиментационного мезоциклита, 8 - биогермы, 9 - мергель $(a)$ и домерит (б), 10 - поверхность перерыва, 11 - трещины усыхания, 12 - крупный детрит, 13 - скопления детрита, 14 - мелкий детрит, 15 - галька известняковая, 16 псаммит и сгустки, 17 - битуминозность, 18 - примесь кукерсита, 19 - узорчатость по тонко-рассеянному пириту, 20 - табуляты массивные, 21 - табуляты ветвистые, 22 - ругозы, 23 - онколиты мелкие полусферические, 24 - онколиты крупные сферические, 25 эвриптериды, 26 - водоросли, 27 - остракоды, 28 - наутилоидеи, 29 - ходы илоедов. 
руженный автором в южной стенке карьера рассмотренный выше маркирующий пласт, сложенный зеленовато-темно-серым тонкослойчатым известковым глинистым доломитом с мелкой пиритовой узорчатостью. Ниже и выше этого пласта залегают массивные кораллово-строматопоровые известняки (рис. 2 и 3). Все слои имеют здесь заметный наклон к югу, обусловленный, видимо, неровностью поверхности подстилающего биогермного комплекса, и поэтому маркирующий пласт в северной части карьера не обнажается.

Рассматриваемый пласт резко отличается от выше- и нижележащих известняков как по цвету, бо́льшему содержанию доломитового и глинистого компонентов, так и по горизонтально тонкослойчатым текстурам и скудным остаткам организмов. Породообразующими в подстилающих и покрывающих слоях являются известковые водоросли, а строматопораты и табуляты отсутствуют в них полностью. В верхней части пласта на некоторых поверхностях напластования присутствуют лишь ориентированные створки крупных лепердитид. В кровле пласта наблюдаются ясные полигональные трещины усыхания, маркирующие границу мезоциклитов.

Выше маркирующего пласта первичных доломитов с перерывом залегает базальная пачка среднего мезоциклита яагарахуского горизонта, сложенная биоморфно-детритовыми остракодовыми и онколитовыми известняками (доломитизированными восточнее линии СаувереКингисепп). Эти онколитовые доломиты обнажаются в окрестностях Маази и Каванди и называются местными жителями луковым плитняком.

По этому реперному стратиграфическому уровню в буровых скважинах можно утверждать, что стратотипические разрезы восточной (Маази) и западной части о-ва Сааремаа (Яагараху) хорошо сопоставимы с разрезом скв. Пангамяги (рис. 2 и 3). Примечательно, что в керне скв. Пангамяги без затруднений можно узнать маркирующий пласт глинистого доломита в кровле вильсандиских слоев, имеющий здесь в три раза бо́льшую мощность, чем в карьере Яагараху. Покрывающий базальный пласт средне-яагарахуского мезоциклита (маазиских слоев) сложен чередующимися слоями микрокристаллического и мелкодетритово-сгусткового известняков с остракодами и редкими строматопоратами. Аналогичная смена пород на этой границе наблюдается в скв. Маази, но вместо строматопорат там встречаются онколиты. Оказывается, что обнажающийся в карьере Маази доломитизированный онколитовый известняк залегает непосредственно над уровнем обнажения Яагараху (рис. 3).

Слои, выделенные в разрезе обнажения Пангамяги, прослеживаются и в разрезе заложенной рядом скважины (рис. 3), детально изученном уже A. Луха (Luha, 1930). Толстослоистые криноидные известняки с многочисленными кораллами и строматопоратами в верхней части уступа Пангамяги вскрыты скважиной до глубины 2,9 м, а залегающие ниже комковатые илисто-детритовые глинистые известняки с волнистыми прослоями мергеля - в интервале 2,9-4,2 $м$. Несколько сот метров севернее обнажения на уровне комковатых известняков в старом окопе вскрыты небольшие биогермы. Ниже биогермов прослеживается маломощный прослой с частыми мелкими просверленными онколитами. Этот онколитовый слой установлен в керне скв. Пангамяги на уровне $4,5 м$ (рис. 3). Данный онколитовый уровень зафиксирован Э. Кала и автором также в ряде других разрезов буровых скважин восточной части о-ва Сааремаа.

Обнажение Пангамяги является стратотипом бывшей пангамяги- 
ской пачки - разнообразного известнякового комплекса, развитого в западной части Сааремаa (Luha, 1930; Аалоэ, 1960). Позднее А. Аалоэ (1970) распространил это название на всю нижнюю часть яагарахуского горизонта. С последним трудно согласиться. По разрезу скв. Пангамяги (рис. 3) видно, что обнажение Пангамяги залегает почти на 10 выше стратотипического обнажения средних (маазиских) слоев. Следовательно, нижняя часть яагарахуского горизонта не может быть названа по обнажению Пангамяги. Учитывая это, в стратиграфической схеме силура Эстонии для всего мезоциклита, охватывающего верхнюю часть яаниской свиты (парамаяскую пачку) и нижнюю часть яагарахуской свиты до кровли маркирующего пласта лагунных доломитов, восстановлено название вильсандиские, предложенное для нижней части яагарахуского горизонта еще X. Беккером (Bekker, 1925; Аалоэ и др., 1976).

Естественной границей вильсандиских и маазиских слоев является граница мезоциклитов на уровне кровли выдержанного пласта известкового глинистого доломита, обнажающейся также в Яагараху, в стратотипическом разрезе яагарахуского горизонта.

Название Пангамяги, по нашему мнению, целесообразно использовать в ограниченном объеме для обозначения биогермных известняков и фациально с ними непосредственно связанных криноидных и коралловых глинистых слабобитуминозных известняков в средней части маазиских слоев. В таком случае пангамягиская пачка - точный фациальный и синфазный аналог кесселайдской пачки, отличающаяся от последней по возрасту и отделенная от нее инофациальными отложениями кровли вильсандских слоев (маркирующий пласт). и нижней части маазиских слоев.

Автор выражает искреннюю благодарность геологам Управления геологии ЭССР М. Реммель, Х: Перенс, Э. Кала и А. Хаас за помощь при изучении кернов новых скважин.

\section{ЛИТЕРАТ У Р А}

А алоэ А. Новое в стратиграфии силура Эстонии. - Тр. Ин-та геол. АН ЭССР, $1960, \mathbf{V}, 123-141$.

А алоэ А. Стратиграфия яаниского горизонта $\left(\mathrm{J}_{1}\right)$ силура Эстонии. - Тр. Ин-та гёол. АН ЭССР, 1961, VI, 13-28.

А а лоэ А. Яагарахуский горизонт. - В кн.: Силур Эстонин. Таллин, 1970, 252-264.

А алоэ А., Кальо Д., Кла аманн Э., Нестор Х., Эйн асто Р. Стратиграфическая схема силура Эстонии. - Изв. АН ЭССР. Хим. Геол., 1976, 25, $38-45$.

Афана асьев С. Л. Методика изучения пульситов (циклокомплексов) флишевой формации. - В кн.; Геоцикличность. Новосибирск, 1976, 100-117.

Нестор В. Зональное распределение хитинозой в яаниском горизонте (венлок Эстонии) и проблема его границ. - В кн.: Стратиграфия древнепалеозойских отложений Прибалтики. Таллин, 1981.

Эйн а сто P. Роотсикюлаский горизонт. - В кн.: Силур Эстонии. Таллин, 1970, $264-276$.

Эй н а сто Р. Принципы выделения и взаимоотношение лито- и циклостратиграфических подразделений силура Прибалтики. - Материалы по стратиграфии Прибалтики. Вильнюс, 1976, 57-59.

Bekker, H. Carte Géologique. - In: Album Statistique. Tallinn, 1925.

E in a sto, R., Kala, E., Perens, H. Ninase kihistiku levikust Saaremaa idaosas. Geoloogilised märkmed, 1976, III, 61-65.

Luha, A. Uber Ergebnisse stratigraphischer Untersuchungen im Gebiete der Saaremaa-Oesel-Schichten in Eesti. - Acta Univ. Tartu, 1930, A18, 6.

Институт геологии

Академии наук Эстонской ССР
Поступила в редакцию $13 / 1111981$ 


\section{JAAGARAHU, PANGAMÄE JA MAASI STRATOTOOPSETE PALJANDITE VANUSELISED VAHEKORRAD (EESTI KESKUENLOK)}

Mesotsükliitide piiri fikseerimine Jaagarahu murru lounaseinas $0,5 \mathrm{~m}$ paksuse savika lubidolomiidikihi ülemisel, kuivuslōhedega kaetud pinnal ja paljudes Saaremaa puuraukudes, kaasa arvatud Pangamäe $(15,3 \mathrm{~m})$ ja Maasi $(4,6 \mathrm{~m})$, võimaldas kindlaks teha, et Pangamäe paljand asub jaagarahu lademe koondprofiilis $8-9 \mathrm{~m}$ lademe keskmiste kihtide stratotüübist, Maasi paljandist, kõrgemal ega saa seetōttu olla jaagarahu lademe alumiste kihtide stratotüübiks. Viimastele on juba H. Bekker andnud vilsandi nime. Pangamäe nime soovitame kasutada kihistiku mahus maasi kihtide keskosas paiknevate biohermide ja nende ümbriskivimite tähistamiseks (analoogiliselt kesselaiu hihistikule vilsandi kihtides).

\section{R. EINASTO}

\section{ON THE RELATIONSHIP OF THE JAAGARAHU, PANGAMĂgI AND MAASI STRATOTYPE SECTIONS (MIDDLE WENLOCKIAN OF ESTONIA)}

In the stratotypical outcrop of Jaagarahu and in the sections of the Pangamägi (at the depth of $15.3 \mathrm{~m}$ ) and Maasi borings $(4.6 \mathrm{~m})$, a boundary of sedimentary cycles marked by mud cracks has been established above calcareous dolomitic mudstone ( $0.5 \mathrm{~m}$ thick). This boundary can be observed approximately $10 \mathrm{~m}$ below the Pangamägi outcrop level and 1-2 $\mathrm{m}$ underneath the Maasi outcrop, i. e., the stratotype of the Maasi Beds. Thus, the Pangamägi outcrop cannot be considered the stratotype of the lowermost part of the Jaagarahu Stage. The term «Pangamägi Member» may be used for the biohermal and adjacent limestones in the middle part of the Maasi Beds. 